\title{
The Roles of Altitude and Fear in the Perception of Height
}

Jeanine K. Stefanucci

William \& Mary

Dennis R. Proffitt

Follow this and additional works at: https://scholarworks.wm.edu/aspubs

\section{Recommended Citation}

Stefanucci, J. K., \& Proffitt, D. R. (2009). The roles of altitude and fear in the perception of height. Journal of Experimental Psychology: Human Perception and Performance, 35(2), 424.

This Article is brought to you for free and open access by the Arts and Sciences at W\&M ScholarWorks. It has been accepted for inclusion in Arts \& Sciences Articles by an authorized administrator of W\&M ScholarWorks. For more information, please contact scholarworks@wm.edu. 


\title{
The Roles of Altitude and Fear in the Perception of Height
}

\author{
Jeanine K. Stefanucci \\ The College of William \& Mary
}

Dennis R. Proffitt
University of Virginia

\begin{abstract}
Previous research on perceiving spatial layout has found that people often exhibit normative biases in their perception of the environment. For instance, slant is typically overestimated and distance is usually underestimated. Surprisingly, however, the perception of height has rarely been studied. The present experiments examined the perception of height when viewed from the top (e.g., looking down) or from the bottom (e.g., looking up). Multiple measures were adapted from previous studies of horizontal extents to assess the perception of height. Across all of the measures, a large, consistent bias was found: Vertical distances were greatly overestimated, especially from the top. Secondary findings suggest that the overestimation of distance and size that occurs when looking down from a high place correlates with reports of trait- and state-level fear of heights, suggesting that height overestimation may be due, in part, to fear.
\end{abstract}

Keywords: height perception, distance perception, perception and emotion, fear of heights, acrophobia

Do heights appear higher when viewed from the top rather than from the bottom? Anecdotal evidence suggests as much. Lafayette Bunnell, in chronicling his battalion's entry into Yosemite in 1851, described his first feelings of seeing El Capitan (the famous 3,000-ft vertical rock formation in the Yosemite Valley) from the bottom as an "imperfect comprehension" (Bunnell, 1990/1892, p. 73). However, once his group climbed further up the mountain and had a chance to look over the cliffs, Bunnell remarked that "from below this seemed insignificant" but that from the top the "level of the valley proper appeared quite distant as we looked down upon it" (p. 80). Similarly, Father Louis Hennepin (1698/1903) grossly overestimated the height of Niagara Falls when he first viewed them from the top on a 1677 expedition. Hennepin estimated the height of the falls to be $600 \mathrm{ft}$, whereas the actual height is only $167 \mathrm{ft}$. He also expressed a fear of the height: "The two brinks are so prodigious high, that it would make one tremble to look steadily upon the water" (Hennepin, 1678/1903).

The aim of the research reported in this article was twofold. The principal goal was to provide a normative description of the perception of distances and sizes viewed vertically. Anecdotal claims suggest that people overestimate vertical distances and

Jeanine K. Stefanucci, Department of Psychology, The College of William \& Mary; Dennis R. Proffitt, Department of Psychology, University of Virginia.

The experiments reported in this article were part of Jeanine Stefanucci's dissertation research conducted at the University of Virginia. This research was supported in part by a Faculty Senate Dissertation Year Fellowship awarded to Jeanine K. Stefanucci and National Institutes of Health Grant RO1MH075781-01A2 to Dennis R. Proffitt. The authors wish to thank Stephen Dewhurst, Blair Hopkins, Steven Marchette, Arielle Myhre, and Daniel Partin for their help in collecting the data and Bill Epstein, Gerald Clore, and Bethany Teachman for their comments on an earlier draft of this article.

Correspondence concerning this article should be addressed to Jeanine K. Stefanucci, Department of Psychology, The College of William \& Mary, P.O. Box 8795, Williamsburg, VA 23187-8795. E-mail: jkstef@wm.edu sizes, especially when viewing the extents from above. A secondary aim was to assess whether the perception of vertical extents is influenced by the observer's fear of the height. Tentatively, we judged that people who are more afraid of heights would overestimate vertical distances and the sizes of objects viewed from those distances more than people who are unafraid would.

In the current studies, we investigated the perception of heights when viewed from both the top and bottom using a variety of converging measures adapted from the study of distance and size perception on horizontal surfaces. Before proceeding further, therefore, we first review the scarce literature on height perception and then discuss the research on horizontal distance and size perception that motivated our choice of methodologies for the current studies.

\section{Vertical Distance Perception: Exocentric Viewing of Heights From Below}

Yang, Dixon, and Proffitt (1999) asked participants to estimate the height of various objects in the real world, with the heights ranging from a little over $2 \mathrm{~m}$ to a little under $14 \mathrm{~m}$.. A visual matching measure was used in which participants positioned a pole to be equidistant in the frontoparallel plane to the height of the object they viewed. An experimenter held the pole and walked out from the object laterally until the observer instructed them to stop. The distance on the ground between the experimenter and the object represented the height of the object.

The larger the object, the more observers overestimated the height of the object relative to the horizontal extent, even though visual angle to all of the objects across participants was held constant. Proportional overestimation of the vertical was calculated by dividing the actual height of the target by the produced horizontal extent. A proportional overestimation of exactly 1.0 indicated a perfect estimate of the height of the object with the horizontal extent. For the objects used in this experiment (given in order of increasing physical size with their proportion overestimation), larger objects were overestimated more than smaller objects: 
door ( $2 \mathrm{~m}), 0.99$; light pole, 1.06; edge of chemistry building, 1.13; edge of psychology building (14 m), 1.18. These findings suggest that heights are overestimated on the ground, but only when they are relatively large.

\section{Vertical Distance Perception: Egocentric Viewing of Heights From Above}

The perception of vertical extents as viewed from a height looking down has only been investigated in two studies that we could locate. Sinai, Ooi, and He (1998) reported that participants who stood at the top of a 6 - $\mathrm{ft}$ vertical drop overestimated the distance to the ground with visual matching (as described above) and blindwalking measures of perceived distance to the ground. The blindwalking measure required the observer to walk a horizontal extent (without vision) that was equivalent to the extent that the observer viewed vertically. They attributed the overestimation of height with these measures to a misperception of eye height and did not include a comparison of viewing the height from the top to viewing the height from the bottom (a potential baseline measure). Jackson and Cormack (2007) showed that heights are overestimated more from the top than the bottom using only visually matched estimates of distance. They suggested that the overestimation from the top was greater because of the evolutionary significance associated with heights in terms of falling (termed the evolved navigation theory).

In sum, the data collected in the few existing studies suggest that heights are overestimated slightly when viewed from the bottom and significantly more so when viewed from the top. Given the scant research to date, more data are needed using a variety of measures adopted from the study of horizontal distance perception. Also, the extent of the height needs to be varied so that we can be sure that the results are generalizable to different locations.

\section{Horizontal Distance Perception}

Many measures of horizontal extents have been employed to understand the normative biases associated with judging ground distances. Here, we discuss the research that has been done in this area and the types of methodologies used in order to motivate our choice of methodologies for the current studies.

Overall, horizontal distance estimates are fairly accurate up to $4 \mathrm{~m}$. They are increasingly underestimated, however, as the distance increases; a typical observer reports a 10-m distance as $9 \mathrm{~m}$ (see Amorim, Loomis, \& Fukusima, 1998; Cutting \& Vishton, 1995; Loomis, Da Silva, Fujita, \& Fukusima, 1992; Norman, Todd, Perotti, \& Tittle, 1996). This underestimation is only observed with certain distance measures and when the judgment is of egocentric distance, so we will discuss the measures that exhibit this bias first.

A common method for obtaining estimates of perceived distance involves asking the observers to replicate the extent they are viewing in an alternate direction (that is, through visual matching). Typically, observers view an extent in front of them and then position two experimenters in the frontoparallel plane to be the same distance from each other as the observer is from the target. When observers are asked to perform this task, they exhibit the typical underestimation described above (Loomis et al., 1992).
Another measure, verbal report of distance, also produces large underestimation (Proffitt, Stefanucci, Banton, \& Epstein, 2003; Witt, Proffitt, \& Epstein, 2004; Stefanucci, Proffitt, Banton, \& Epstein, 2005; also see Philbeck \& Loomis, 1997). Verbal reports require the participant to estimate an extent by using either conventional metric representations of a foot, ruler, meter, or other unit of measure, or by holding a ruler while making the estimate. However, when participants estimate distance in this way, they typically underestimate distances that are farther than about $4 \mathrm{~m}$.

In contrast to the measures of distance discussed above, other distance measures do not seem to exhibit large underestimations (for a comparison of measures see, Andre \& Rogers, in press). One example is a measure that requires the observer to walk to a previously viewed target without vision (termed blindwalking). Blindwalking is an example of an open loop, visually directed action that many studies have used as a measure of distance perception (Corlett, Patla, \& Williams, 1985; Elliott, 1987; Loomis et al., 1992; Rieser, Ashmead, Talor, \& Youngquist, 1990; Steenhuis \& Goodale, 1988; Thomson, 1983). In a typical experiment, the participants view a target on the ground and then are asked to close their eyes and walk to the target's location. Because the participants' eyes are closed, they must rely on updating their body movement through proprioceptive or vestibular cues to perform the task. Interestingly, participants are quite accurate at reproducing the distance, even when the target is placed up to $20 \mathrm{~m}$ away.

Another measure of visually directed walking that can be used to measure distance is triangulation-by-walking (Fukusima et al., 1997; Loomis et al., 1992). The distance to the target is measured by asking participants to view the target and walk with their eyes closed on an oblique path from the target until they are asked to turn and face the target and take a few steps toward it. Perceived distance is calculated by measuring the participant's orientation after the turn compared to their original viewing direction. Again, participants are fairly accurate at reporting distance using this methodology, but they could be representing the location of the target to guide their action without needing to calculate the distance to the target.

However, it should be noted that both blindwalking and triangulated blindwalking could also be considered measures of apparent location rather than apparent distance (for a discussion of this issue, see Proffitt, Stefanucci, Banton, \& Epstein, 2007). When viewing a target on the ground plane, its location can be updated relative to its angular elevation scaled to eye height, as opposed to egocentric distance. When viewing targets that are not on the ground plane-such as vertical extents viewed from above or below-eye height is not informative, and, thus, updating would more likely rely upon apparent distance.

\section{Size Perception}

Estimates of the size of an object placed at a particular distance can sometimes serve as indirect measures of the apparent horizontal distance to the object. The size-distance invariance hypothesis states that people perceive the size of an object by relating retinal size to distance (Epstein, 1973; Gilinsky, 1951; Kilpatrick \& Ittelson, 1953; Rock, 1975). This account predicts that inaccuracies in distance perception will result from inaccuracies in size perception. The distance scaling of size is especially likely in situations when the observer is viewing a vertical extent because 
the eye-height scaling of size cannot be achieved when an observer is not standing on the ground (Wraga \& Proffitt, 2000). Therefore, objects should be perceived as larger from a height if the height is overestimated. However, size perception need not relate to distance estimates. Geometrical inconsistencies have been found in studies examining the size-distance invariance hypothesis (Epstein, 1977; Epstein, Park \& Casey, 1961; Sedgwick, 1986), and they may occur in the current studies. Regardless, size perception can also serve as another index of the influence of fear on the perception of spatial layout.

Experiments on perceived size employ two general measures. In a method similar to distance estimation, observers are often asked to give verbal reports of the size of objects by estimating some dimension of the object (e.g., width or height). Again, observers are assumed to use a conventional metric to make their estimates and are accurate when the distance to the object is not far (Gilinsky, 1955). In other experiments, observers are asked to adjust the size of a closer target to match that of a target at a distance. When this measure is used, observers sometimes overestimate the size of farther objects even when viewing them in full-cue outdoor environments (Gilinsky, 1951; Leibowitz \& Harvey, 1967; 1969). Similar results have also been obtained in reduced-cue, indoor environments (Holway \& Boring, 1941). All of these experiments reported overconstancy (the tendency to increase estimates of perceived size as the distance to the object increases). Indeed, the overestimation of size reached a factor of 3 to 4 as the viewing distance increased by a factor of 10 .

\section{Is Overestimation of Height a Perceptual Paradox?}

The current studies question whether people normatively overestimate heights. If vertical distances are normatively overestimated, then this finding is in contrast to predictions of general theories of distance perception pertaining to horizontal distances (for a review, see Sedgwick, 1986). Horizontal distances are typically underestimated, especially in reduced-cue environments (Gogel, 1965; Philbeck \& Loomis, 1997). One might wonder why vertical distances are normatively overestimated given that viewing the height from above also reduces the cues available for estimating distance. When viewing from the top, the horizon and the observer's eye height are useless cues for distance because the observer is not viewing an extent on the ground plane. Also, texture gradient is a minimal cue to distance from the top, but it is usually available when viewing a height from the bottom. Notably, a reduction of the optical variables used to scale distance on the ground plane usually leads to an underestimation of horizontal distance (Gogel; Philbeck \& Loomis). Philbeck and Loomis reduced cues to distance, including motion parallax, binocular parallax, and angular elevation, and found that both blindwalked and verbal reports of horizontal distances were underestimated when the availability of these cues was poor. Gogel asserted that, when all information for distance was eliminated, observers usually reported an endogenously supplied perceived distance that was related to the resting state of accommodation (a distance close to arm's reach or $2 \mathrm{~m}$ ). He suggests that this specific distance tendency is typically an underestimation of the actual distance and is the default distance estimate when no definitive depth cues are available. If vertical extents are normatively overestimated, especially when viewed from the top or in a reduced-cue situation, then this is somewhat paradoxical given previous findings with horizontal distance perception in reduced-cue environments.

It is possible that fear evokes an overestimation of height, particularly when heights are viewed from the top. Previous research showed that fear influenced the perception of other aspects of spatial layout, like the perception of geographical slant. Proffitt, Bhalla, Gossweiler, \& Midgett, (1995) found that estimates of the slant of hills differed when viewed from the top or the bottom of the hill. For the three steepest hills in their studies, $\left(31^{\circ}-34^{\circ}\right)$, participants perceived the inclination to be greater from the top than the bottom. The authors suggested that this reflected an asymmetry in participants' natural ability to ascend versus descend steep hills. Participants may have viewed the hills as steeper from the top because of the danger involved in descending them. Indeed, if the participant was pushed at the top of a hill greater than $30^{\circ}$, they would be forced to break into a run to descend the hill and would likely fall down. This finding suggests that the difference in overestimation from the top of hills may be due to perceived danger or fear associated with descending the steep incline.

To follow up on this hypothesis, Stefanucci, Proffitt, Clore, and Parekh (2008) tested whether the perception of slant was influenced by the fear associated with a potentially dangerous action directed at the hill. Participants were situated at the top of a hill and stood either on a skateboard or on a wooden box of the same height. They gave estimates of the slant of the hill and then reported their fear of descending the hill. Those participants who stood on the skateboard and reported feeling frightened perceived the hill as steeper than those participants who stood on the box and were unafraid. This study provided initial evidence that fear influences the perception of geographical slant.

Recent work by van Ulzen, Semin, Oudejans, and Beek (2008) has also found an influence of affective content on size perception. In two experiments, they show that circles containing a negative image were judged to be larger than circles containing a positive or neutral image and that this overestimation of size in the negative condition weakened the Ebbinghaus illusion when the negative target was flanked by positive or neutral images.

In addition, clinical psychologists who study phobias have long suggested that fear affects perception (Hekmat, 1987; Rachman \& Cuk, 1992; Weerts \& Lang, 1978). These clinicians have reported perceptual biases among their patients that suggest that the visual worlds of people with phobias are unique. People with a fear of heights report bridges and buildings to be longer and higher (Rachman \& Cuk); people with a fear of spiders imagine the threatening stimuli as more vivid and unpredictable (Riskind, Kelly, Moore, Harman, \& Gaines, 1992). However, many of the attempts to quantify differences in the visual worlds of people with extreme fears have been unsuccessful because the measures used to assess visual experiences were cognitive rather than perceptual. Radomsky, Teachman, Baker, and Rachman (1996) had participants estimate the height of a balcony from memory, not while they viewed the height. Therefore, we could not be sure that the fear effect was due to a change in the way the person saw the world rather than how they remembered or interpreted the world, given the fear they experienced while viewing the height.

Although testing the influence of fear on the perception of height was not the primary aim of the current studies, assessments of fear were introduced following the perceptual measures to begin to explore this hypothesis. 


\section{Overview of Studies}

Studies of the perception of spatial layout suggest that normative biases occur in the perception of distance and slant. Do biases also occur in the perception of heights when viewed from the top or the bottom? Drawing upon previous research, the behavioral studies presented in this 'article tested this hypothesis with a variety of measures, including both direct and indirect measures of distance perception and measures of size perception. We included the indirect measure, triangulation by walking, to reduce the likelihood that participants would infer the purpose of the experiment and influence their estimates accordingly. In addition, we included state and trait-level measures of individual differences in fear of heights to preliminarily investigate whether fear moderates these normative estimates.

\section{Experiment 1A: Visually Matched Estimates of Height and Size From the Top and Bottom}

\section{Method}

Participants. Forty-eight University of Virginia undergraduate students ( 32 women, 16 men) participated in the experiment for a free snack. Sixteen women and 8 men each were in the top- and bottom-viewing conditions.

Apparatus. An 8-m balcony was used in the experiment. The balcony was $2.53 \mathrm{~m}$ wide and $38.86 \mathrm{~m}$ long. Participants stood $10.5 \mathrm{~m}$ from one end of the balcony to view the target. A large orange disk made of core board $(45.72 \mathrm{~cm}$, or $18 \mathrm{in}$., in diameter) marked the distance to be judged. Tape measures were used to record the participants' size and distance estimates.

Participants completed the Anxiety Subscale of the Acrophobia Questionnaire (AQ, Cohen, 1977) to measure general fear associated with heights. This scale measures the degree to which a person has fear-relevant thoughts during exposure to different types of heights. People who have acrophobia typically score a 60 or above. Possible scores range from 0 to 120 .

In addition, participants reported their state fear levels during exposure to the heights in these experiments. State fear was assessed using verbal reports on a 0-to-100 scale, the Subjective Units of Distress Scale (SUDS), with 100 reflecting extreme fear. These fear ratings served as a measure of fear associated with the specific height used in the experiments.

Design. Participants were randomly assigned to either the topor bottom-viewing condition (see Figure 1). Each participant made one estimate of the distance from themselves to the target disk and one estimate of the size of the target.

Procedure. Participants who viewed the height from the top stood at the edge of a two-story balcony (there was a railing in front of the participant) with the target disk placed on the ground beneath the balcony. After viewing the target, they estimated the height of the balcony by trying to position an experimenter to be the same distance from them along the balcony as the participant was to the target on the ground. After viewing the target, they estimated the height of the balcony from the railing to ground by trying to position an experimenter to be the same distance from them along the balcony as the railing was to the target on the ground. Participants were encouraged to look back and forth at the target and the experimenter as often as they liked. Participants who

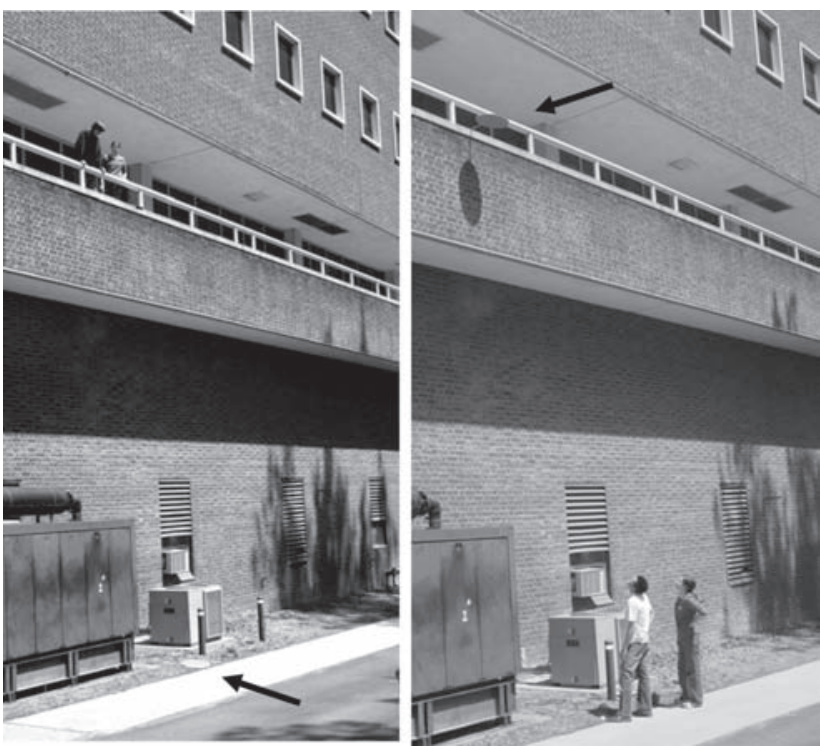

Figure 1. Viewing locations for the top (left) and bottom (right) viewing conditions in Experiments 1A and 2. The arrows point to the targets.

stood on the ground viewed the balcony with the target suspended from the railing. They also estimated the height of the balcony, specifically from their feet to the top of the railing, by positioning an experimenter to be the same distance from them as their feet were from the target. All participants gave visual-matching size estimates of the target disk by adjusting a tape measure in the frontal plane to match the diameter of the target as if it were on the ground plane in front of them. The metric markings on the tape measure faced away from the participants. The participants were allowed to look back and forth between the experimenter and the target as much as they liked.

After the two estimation tasks, participants completed the SUDS and AQ (in that order) and received a snack.

\section{Results}

Height. Participants in both viewing conditions overestimated the height of the balcony, but the overestimations made by those in the top-viewing condition were significantly greater than the overestimations made by those in the bottom-viewing condition (see Figure 2a). A one-way analysis of variance (ANOVA) showed that height estimates made from the top $(M=12.57, S D=3.12)$ were significantly larger than those made from the bottom $(M=9.71$, $S D=1.79), F(1,47)=15.10, p<.0001, \eta_{p}^{2}=0.23$. Participants who viewed the height from the top overestimated by $60 \%$, whereas participants who viewed the height from the bottom overestimated by only $29 \%$. The magnitude of overestimation difference between the top and bottom condition was $31 \%$.

Size. Participants also overestimated the size of the target disk when viewing from the top, but not when viewing from the bottom (see Figure 2b). A one-way ANOVA showed that the size overestimation from the top $(M=57.00, S D=10.90)$ was significantly different from the estimates made from the bottom $(M=$ 46.89, $S D=8.39), F(1,47)=12.97, p=.001, \eta_{p}^{2}=0.20$. Participants who viewed the target from the top overestimated its 

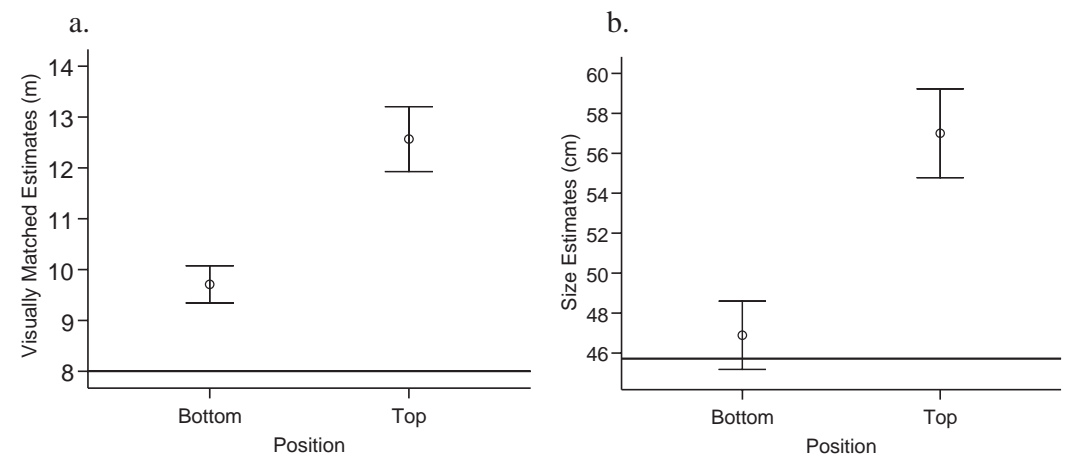

Figure 2. a) Height estimates for the top and bottom viewing conditions in Experiment 1A. The line denotes the actual height of the balcony $(8 \mathrm{~m})$. b) Size estimates for the top and bottom viewing conditions in Experiment 1A. The line denotes the actual size of the target $(45.72 \mathrm{~cm})$. All bars represent one standard error of the mean.

size by $24.6 \%$, whereas participants who viewed the target from the bottom overestimated its size by only $2.5 \%$. The magnitude of overestimation difference between the top- and bottom-condition was $22 \%$.

Fear. On average, participants who viewed the height from the bottom reported low feelings of state-level fear on the SUDS $(M=9.42, S D=11.86)$ and fairly low trait-level fear on the AQ $(M=27.17, S D=14.42)$. This is not surprising given they were on the ground and were nonacrophobes. The participants in the top-viewing condition reported higher state-level fear $(M=19.00$, $S D=16.76)$ than the bottom participants, $F(1,47)=5.23, p=$ $.03, \eta_{p}^{2}=0.10$. The top participants' trait-level reports of fear on the AQ $(M=30.25, S D=14.16)$ were not different from the bottom condition and were also well below the acrophobe range. Overall, participants' state and trait-level reports of fear were positively correlated, regardless of the viewing condition, $r(47)=$ $0.50, p<.0001$.

To test whether fear moderated the overestimation of height, the height and size estimates were correlated with participants' ratings of state-level fear on the SUDS and their trait-level fear score on the AQ. There was a positive correlation between SUDS ratings and the height estimates, $r(47)=0.42, p=.003$, and a similar trend for the size estimates, $r(47)=0.27, p=.06$ (see Figure 3a and $3 \mathrm{~b}$, respectively). Participants who were more anxious about the balcony (higher scores on the SUDS) estimated the height to be taller and the size of the target to be larger. In addition, there was a positive correlation between participants' scores on the AQ and their height estimates, $r(47)=0.33, p=.02$ (see Figure 4). In contrast, there was no relationship between scores on the AQ and size estimates, $r(47)=0.14, p=.33$. Participants who had scored a.

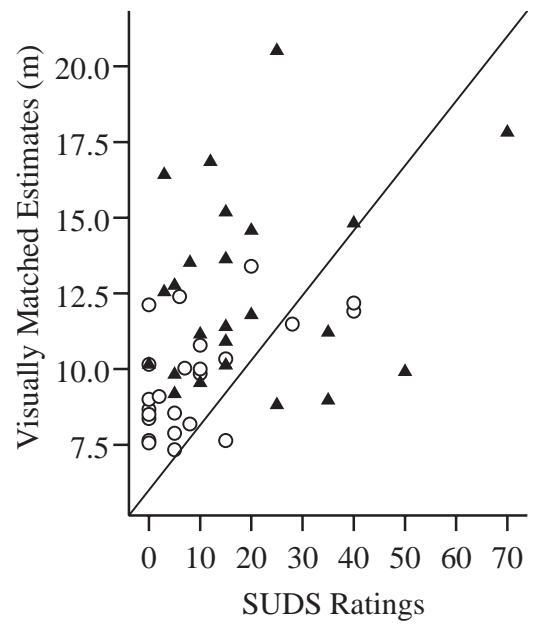

b.

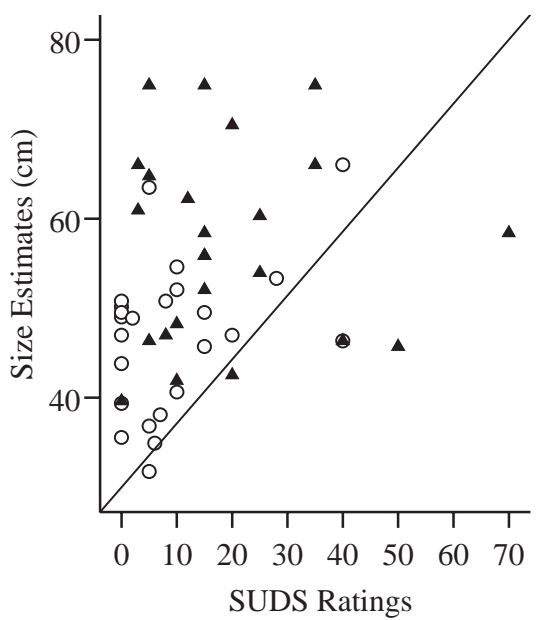

Figure 3. a) Relationship between height estimates and state-level fear ratings on the Subjective Units of Distress Scale (SUDS) in Experiment 1A. b) Relationship between size estimates and state-level fear ratings (SUDS) in Experiment 1A. In both graphs, the triangles represent participants who viewed the balcony from the top and the circles represent participants who viewed the balcony from the bottom. 


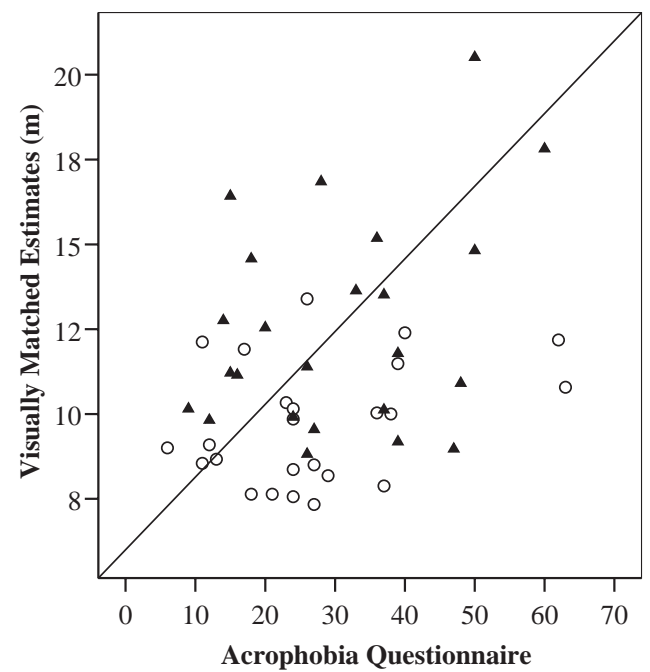

Figure 4. Relationship between height estimates and trait-level fear ratings on the Anxiety Subscale of the Acrophobia Questionnaire (Cohen, 1977) for the top- (triangles) and bottom- (circles) viewing conditions of Experiment $1 \mathrm{~A}$

higher on the AQ perceived the height of the balcony as taller but the target did not appear bigger.

\section{Discussion}

When participants stood on the top of a balcony, they estimated its height to be $31 \%$ taller than did participants who stood at the bottom. Accordingly, participants who viewed from the top also overestimated the size of a target on the ground to be $22 \%$ larger than participants who viewed the same target from the ground. The results of the size-estimation task suggest that other measures of spatial layout elicit similar overestimations when compared to distance estimation tasks. Furthermore, both results suggest that a gross overestimation of height and size are observed when participants view from the top compared to the bottom.

The overestimation of size from the top is an important finding because it controls for a potential confound in this experiment. Specifically, participants in the top-viewing condition may have estimated the height of the balcony to be taller because the distance actually is greater if they are judging from their eye height to the target. However, the estimates of the size of the target should have been accurate in both the top- and bottomviewing conditions if the distance estimates were accurate (which one would expect if participants judged from their eye height). The overestimation of the size of the target from the top provides further evidence for an overestimation of apparent distance. Thus, in addition to providing an important converging measure of distance perception, the size-matching task controlled for the possible influence of eye height on apparent distance between the topand bottom-viewing conditions.

The overestimation of height with the visual matching task was also correlated with participants' state- and trait-level fear of heights. Even though participants were nonacrophobes, their estimates of the height correlated with their fear of heights in both viewing conditions. This finding was surprising because we had thought that the fear measures would be more likely to correlate with the estimates from the top. One possible explanation for this finding is that people who are afraid of heights are simply influenced by the appearance of a height, regardless of where they stand to view it. The sight of the height may be enough to trigger their state- or trait-level fears associated with heights and influence their estimates from the top or the ground. However, it should be noted that the trait-level ratings of fear only correlated with the height estimates, not the size estimates. This finding suggests that people with a trait-level fear of heights may only overestimate the parameter that is related to their fear. In other words, it may not be that everything in the environment becomes larger when someone high in height fear views a height, but rather that only the elicitor of their fear, the height itself, is distorted.

One potential problem with this experiment is that the overestimation of height from the top may be due to looking down in general. The act of looking down may have resulted in the large overestimation from the top. Experiment 1B was performed to assess whether looking down resulted in an overestimation of a lower height. The experiment was also performed to estimate the range of extents for which this overestimation occurs from the top. Lower heights may not be overestimated because they do not evoke fear and optical cues that specify distance are more apparent at these locations.

\section{Experiment 1B: Visually Matched Estimates of a Lower Height From the Top}

\section{Method}

Participants. Twenty-four University of Virginia undergraduates (18 women, 6 men) participated in the experiment for a free snack.

Apparatus. A lower balcony $(1.60 \mathrm{~m})$ was used in this experiment. A large orange disk made of core board $(45.72 \mathrm{~cm}$ in diameter) marked the distance to be judged. Tape measures were used to record the size and distance estimates.

Procedure. In this experiment, all participants viewed the height from the top of the balcony. The bottom-viewing condition was not run because the target was either at or below eye level for most of the participants. All participants stood on the balcony and estimated the distance to the target and the size of the target as in Experiment 1A. All participants completed the SUDS and AQ after the perceptual estimates.

\section{Results}

Height. A one-sample $t$ test was performed to determine whether the height estimates from the top of the small height were different from the actual height of the balcony. Visually matched estimates of the height were significantly greater than the actual height of the balcony, $t(1,23)=2.75, p=.01, d=0.83$. On average, participants estimated the height of the balcony to be $1.84 \mathrm{~m}(S D=0.39)$ tall. This represented a $14 \%$ overestimation of the actual height of the balcony. Participants overestimated the height of a lower balcony, but not to the extent of the overestimation observed in Experiment 1A.

Size. A one-sample $t$ test showed that size estimates of the target were not significantly different from the actual size of the 
target, $t(1,23)=-1.60, p=.12$. On average, participants estimated the size of the target to be $43.97 \mathrm{~cm}(S D=5.33)$ wide. This represented a $4 \%$ underestimation of the actual size of the target. Size estimates were positively correlated with height estimates, $r(23)=0.48, p=.02$. Even though participants showed an overestimation of height with the distance measure, they did not overestimate the size of the target.

Fear. To test whether fear moderated the overestimation of height, we correlated the height and size estimates with participants' SUDS ratings and their scores on the AQ. Overall, SUDS ratings were low $(M=5.29, S D=4.68)$ and AQ scores were a little higher than in the previous experiment $(M=32.83, S D=$ 18.07). Participants' scores on the SUDS and AQ were highly correlated, $r(23)=0.58, p=.003$. There was a negative correlation between participants' scores on the AQ and their size estimates, $r(23)=-0.44, p=.03$. Participants who had higher trait-level fear estimated the size of the target to be smaller, so it does not seem as if fear moderated the perception of height in this experiment. There was no relationship between SUDS ratings and size estimates, $p=.30$ or height estimates, $p=.83$. There was also no relation between participants' height estimates and their scores on the AQ, $p=.41$.

\section{Discussion}

This experiment suggests that participants do not overestimate a small height from above as much as the larger height used in Experiment 1A. Therefore, looking down in general seems to produce about half of the overestimation of height (14\%) compared to that observed in Experiment 1A (60\%). Also, there was no overestimation of size, suggesting that the participants in this experiment may have used their eye height to scale distance to the object (rather than judging from the railing as they were told), which did not result in an overestimation of size.

The overestimation of height did not correlate with state- or trait-level fear. This is not surprising, given that the height was not tall and probably did not evoke physiological fear responses. Also, participants with higher trait-level fear estimated the size of the targets to be smaller, suggesting an opposite trend from the previous experiment.

\section{Experiment 1C: Visually Matched Estimates of Height} and Size From the Top and Bottom of a Different Height

This experiment was similar to Experiment 1A, except that a different location was used. This experiment examined whether the effect seen in the previous experiment (1A) was specific to optical cues available at the location of that balcony. In addition, the use of a slightly taller balcony in this experiment could increase participants' fear associated with the height.

\section{Method}

Participants. Forty-eight University of Virginia undergraduates (31 women, 17 men) participated in the experiment for $\$ 4$ or for a course requirement. There were 13 women in the bottomviewing condition and 18 in the top-viewing condition. There were 11 men in the bottom-viewing condition and 6 in the top-viewing condition. Due to an experimenter error, data for the AQ was not recorded for one participant in the top condition.

Apparatus. The balcony used in this experiment was $10.06 \mathrm{~m}$ high. The same orange disk used in Experiments 1A and 1B (45.72 $\mathrm{cm}$ in diameter) marked the distance and size to be judged. Tape measures were used to record the size and distance estimates.

Measures. In addition to the SUDS and AQ, participants rated and then estimated the likelihood of being injured if they fell from the height ( 0 being no injury at all and 100 being death). We introduced this measure to deliberately make participants think about the danger and costs associated with the environment.

Design. Participants were randomly assigned to the top- or bottom-viewing condition. Each participant estimated the distance to or from the waist-high wall on the outer edge of the balcony and then the size of the target disk.

Procedure. The only slight difference between this experiment and the previous experiments included the addition of the injury rating and a slight change in the way participants performed the matching task. However, the matching task in this experiment differed slightly from Experiment 1A. Because the balcony was not wide enough to conduct the matching task to the side of the participants, participants at the top and the bottom of the height were asked to turn around 180 degrees to move an experimenter to be the same distance from as the balcony wall or their fee were from the target. Also, participants were asked to complete the SUDS rating, then they gave their injury rating, and then they completed the AQ.

\section{Results}

Height. As in Experiment 1A, participants in the top-viewing condition overestimated the height of the balcony with the visual matching task to a greater degree than did participants in the bottom condition. (see Figure 5a). A one-way ANOVA showed that height estimates made from the top $(M=17.60, S D=4.72)$ were significantly larger than those made from the bottom $(M=$ $12.68, S D=3.07), F(1,47)=18.33, p<.0001, \eta_{p}^{2}=0.29$. Participants who viewed the height from the top overestimated by $74 \%$, whereas participants who viewed the height from the bottom overestimated by $26 \%$. The magnitude of overestimation difference between the top and bottom condition was $48 \%$.

Size. As in Experiment 1A, participants overestimated the size of the target disk when viewing from the top, but not when viewing from the bottom (see Figure 5b). A one-way ANOVA showed that the size overestimation from the top $(M=56.91, S D=13.43)$ was significantly different from the estimates made from the bottom $(M=48.16, S D=10.93), F(1,47)=6.14, p=.02, \eta_{p}^{2}=0.12$. Participants who viewed the target from the top overestimated its size by $24 \%$, whereas participants who viewed the target from the bottom overestimated its size by only $5 \%$. The size estimates were positively correlated with the height estimates, $r(46)=0.56, p<$ .0001 .

Fear. On average, participants who viewed the height from the bottom reported low feelings of state-level fear on the SUDS question $(M=12.21, S D=13.10)$ and low trait-level scores on the AQ $(M=29.75, S D=14.93)$. Again, the state-level ratings are not surprising given that these participants were standing on the ground. The bottom participants' ratings of injury due to falling from the height were in the middle of the range of possible scores 
a.

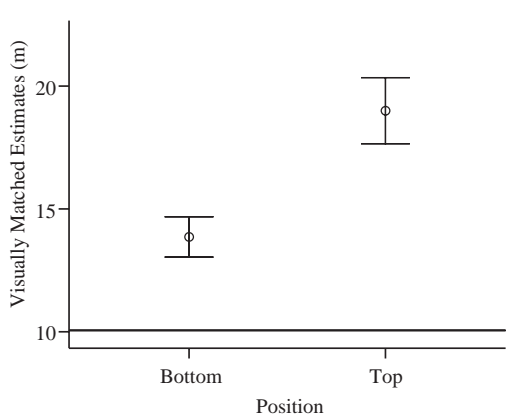

b.

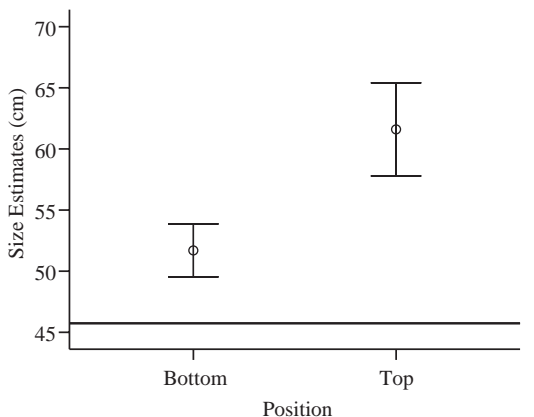

Figure 5. a) Height estimates for the top and bottom viewing conditions in Experiment $1 \mathrm{C}$. The line denotes the actual height of the balcony $(\sim 10 \mathrm{~m})$. b) Size estimates for the top and bottom viewing conditions in Experiment $1 \mathrm{C}$. The line denotes the actual size of the target $(45.72 \mathrm{~cm})$. All bars represent one standard error of the mean.

$(M=57.21, S D=25.01)$. The participants in the top-viewing condition reported significantly higher state-level fear $(M=26.06$, $S D=24.10)$ than the bottom participants, $F(1,47)=6.12, p=$ $.02, \eta_{p}^{2}=0.12$. The trait-level reports of fear for participants viewing from the top on the AQ $(M=35.78, S D=19.73)$ were not significantly higher than those of the participants viewing from the bottom, $p=.24$, and were also well below the acrophobe range. The top participants' ratings of injury due to falling from the height were fairly high $(M=68.13, S D=21.61)$, but were not significantly higher than the bottom participants' ratings, $p=.11$. Interestingly, participants' state and trait-level reports of fear were not correlated, regardless of the viewing condition, $p=.13$, though there was a trend in this direction. Also, AQ scores were not correlated with injury scores, $p=0.52$. However, injury ratings and SUDS scores were correlated for participants viewing from the top, $r(22)=0.44, p=.03$, and the overall correlation, regardless of condition approached significance, $r(46)=0.26$, $p=.07$.

To test whether fear was a factor that moderated the overestimation of height, we correlated the height and size estimates with participants' ratings of state-level fear on the SUDS question, their ratings of potential injury, and their trait-level fear score on the AQ. There was a positive correlation between SUDS ratings and the size estimates, $r(46)=0.28, p=.05$, but no relation between SUDS scores and height estimates, $p=.44$. Participants who were more anxious about the balcony estimated the size of the target to be larger. Trait-level fear, as measured with the AQ, did not relate to the height or size estimates, $p=.84$ and 0.62 , respectively. Predicted injury sustained from falling also did not correlate with the height or size estimates, $p=.12$ and 0.72 , respectively. Interestingly, injury ratings, SUDS ratings, and scores on the AQ did not correlate with each other.

\section{Discussion}

This experiment replicated the overestimation of height and size observed in Experiment 1A. It shows, therefore, that the results from previous experiments were not due to the particular balconies used in those experiments.
However, the overestimation of height was not related to participants' state- or trait-level ratings of fear. Participants' size estimates were positively correlated with their state-level fear ratings, but this correlation was small. Therefore, the conclusions about fear (state- or trait-level) influencing perception are tentative at best. Participants had to turn farther away from the height to perform the matching task in this experiment, which may have reduced their state-level fear associated with the height. Also, participants were randomly selected from the participant pool, and the group of participants in this experiment may have not been as afraid of heights (trait-level) as the group in Experiment 1A. Other differences in the heights could also have resulted in reduced fear reactions. For example, the balcony used in Experiment 1A had a steel railing, whereas the balcony used in this experiment had a solid brick wall at waist height to prevent participants from falling. The brick wall may have made them feel safer.

Also, it is important to note that fear of falling (as assessed by the injury or SUDS rating) may not be the only relevant variable of interest when assessing fear of heights, which could account for an inconsistency in the findings with the fear measures that were used across these studies. In fact, most people with fear of heights express multiple fears related to being in a high place, and some seem not to have a fear of falling at all (Menzies \& Clark, 1995). Instead, many report a fear of losing control or panicking while on the height that would put them in danger (i.e., 'fear of fear'). Thus, likelihood of injury is not the only relevant variable for describing the relationship between actual and estimated distance and size, and measuring the fear reactions in a more individualized way is outside of the scope of this article.

\section{Experiment 2: Multiple Size Estimates from Top, Bottom, and Horizontal}

\section{Viewing Angles}

Experiment 2 tested whether participants overestimated height by examining a range of target sizes. In addition, a horizontalviewing condition was introduced to serve as a baseline for participants' estimates of distance and size. This baseline was em- 
ployed to confirm that there was nothing about the particular target used in the previous experiments that resulted in abnormal size or distance estimates. Also, repeated estimation of size allowed for a test of whether fear influences the slope of the function of size estimates or the intercept of the function.

\section{Method}

Participants. Seventy-two University of Virginia undergraduates (36 women, 36 men) participated in the experiment for $\$ 5$. There were 13 women in the horizontal-viewing condition and bottom-viewing conditions and 10 women in the top-viewing condition. There were $11 \mathrm{men}$ in the horizontal- and bottomviewing conditions and 14 men in the top-viewing condition.

Apparatus. The balcony used was the same as that described in Experiment 1A. Additional targets were added to test a range of sizes. The targets, all different colors, were made of core board. The pink target was $17.78 \mathrm{~cm}$ in diameter, the yellow target was $31.75 \mathrm{~cm}$, the orange target (used in the previous experiments) was $45.72 \mathrm{~cm}$, and the red target was $59.69 \mathrm{~cm}$.

For the horizontal-viewing condition, the targets were displayed on a metal speaker stand that was $1.07 \mathrm{~m}$ tall. Magnets affixed to the back of the targets enabled them to be easily attached and removed from the top of the stand. The stand was placed $8 \mathrm{~m}$ from the participants' feet along the horizontal ground plane.

Design. Participants were randomly assigned to the top-, bottom-, or horizontal-viewing condition. Each participant estimated the size of each of the four target disks once. The order of presentation of the four targets was randomized. Each participant also made one estimate of the distance from oneself to the target disk viewed at that time. In the top-viewing condition, participants estimated the distance from the top of the railing (approximately waist high) to the ground. In the horizontal- and bottom-viewing conditions, participants estimated the distance from their feet to the target.

Procedure. As in the previous experiments, the target was displayed for the participants, and they adjusted a tape measure held by the experimenter to be the same length as the diameter of the target. The order of presentation of the targets was randomized and counterbalanced across conditions. Participants would turn $\left(180^{\circ}\right)$ away while the targets were being switched by the other experimenter.

After estimating the sizes of the four targets, participants were asked to estimate the distance to the final target by performing the visual matching task described in the previous experiments.

Finally, all participants completed the SUDS and then the AQ. In addition, participants in the horizontal-viewing condition were asked to report their general level of anxiety while standing on the horizontal ground plane for the SUDS.

\section{Results}

Size. A 4 (target size) $\times 3$ (condition) repeated measures ANOVA was performed with target size as a within-subjects variable and condition as a between-subjects variable. As expected, the analysis indicated a within-subjects effect of size, $F(3$, $207)=706.47, p<.0001, \eta_{p}^{2}=0.91$, and a between-subjects effect of condition, $F(1,69)=10.68, p<.0001, \eta_{p}^{2}=0.24$. Post hoc analyses using Tukey's HSD showed that participants in the top-viewing condition estimated the size of the targets to be significantly greater than participants in the bottom- and horizontal-viewing conditions, $p<.001$ and $p=.004$, respectively. This difference was significant for each target size (see Table 1). The horizontal and bottom conditions' size estimates were not significantly different from one another, $p=.51$. There was no Size $\times$ Condition interaction, $p=.07$, though it trended toward significance.

Height. A one-way ANOVA comparing the visually matched estimates of distance for each condition revealed that there was an effect of condition on estimates of distance, $F(1,69)=55.80, p<$ $.0001, \eta_{p}^{2}=0.61$ (see Figure 6). Post hoc analyses using Tukey's HSD showed that the top- $(M=11.95, S D=1.99)$, bottom- $(M=$ $10.14, S D=1.88)$, and horizontal- $(M=6.86, S D=1.03)$ viewing conditions were all significantly different from each other, $p=.001$ for the bottom and top comparison, $p<.0001$ for the bottom and horizontal comparison, and $p<.0001$ for the top and horizontal comparison. The top-viewing condition showed a $52 \%$ overestimation, the bottom condition showed a $29 \%$ overestimation, and the horizontal condition underestimated the distance by $13 \%$. There was no correlation between the last target size viewed and the distance estimate, $p=0.41$, so it does not seem as if the finally viewed target size was related to participants' estimates of the distance to the target.

Fear. Average error in size estimation was computed by subtracting actual size of the target from participants' size estimates for that target. Underestimations of size were set to zero, though there were only a few underestimations and they were all in the horizontal-viewing condition. Deviations from the actual size for each target size were added together and the resulting number was divided by four (the total number of targets).

To test whether fear moderated the overestimation of height, average error in size estimates was correlated with participants' SUDS ratings and their scores on the AQ. Participants' scores on the two fear scales were correlated, $r(71)=0.36, p=.002$. There

Table 1

Size Estimates for Top-, Bottom-, and Horizontal-Viewing Conditions in Experiment 2

\begin{tabular}{cccccccc}
\hline & \multicolumn{3}{c}{ Mean size estimate } & & \multicolumn{3}{c}{ Percentage overestimation } \\
\cline { 2 - 3 } Actual size & Top & Bottom & Horizontal & & Top & Bottom & Horizontal \\
\hline 17.78 & $27.57(7.26)$ & $23.30(3.63)$ & $19.90(3.55)$ & & 22 & 31 & 12 \\
31.75 & $47.20(10.98)$ & $39.68(5.78)$ & $36.71(7.00)$ & & 49 & 25 & 16 \\
45.72 & $62.18(11.93)$ & $54.91(10.75)$ & $52.49(11.52)$ & & 36 & 20 & 15 \\
59.69 & $82.16(15.43)$ & $69.51(13.11)$ & $67.00(12.75)$ & & 38 & 16 & 12 \\
\hline
\end{tabular}

Note. Standard deviations are in parentheses. $N=24$ for each cell. 


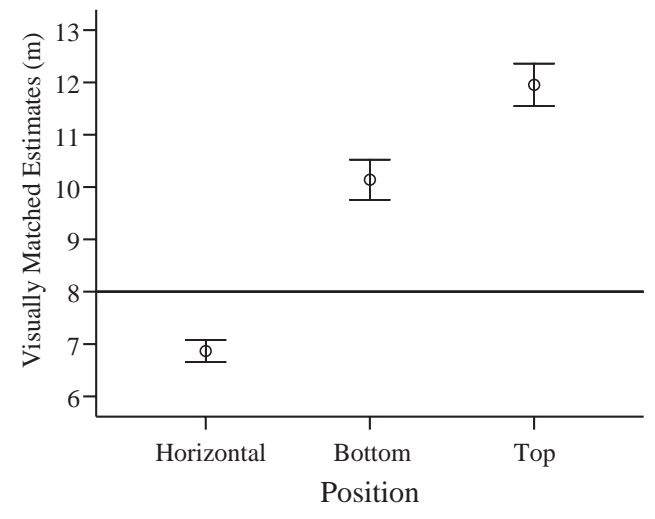

Figure 6. Height estimates for the horizontal-, bottom-, and top-viewing conditions in Experiment 2. The line denotes the actual distance to the target $(8 \mathrm{~m})$. The bars represent one standard error of the mean.

was a positive correlation between participants' SUDS ratings and the average error of their size estimates, $r(71)=0.30, p=.01$ (see Figure 7). Participants who had higher state-level fear perceived larger targets. There was no relation between scores for the AQ and size estimates, $p=.76$, or distance estimates, $p=.46$. There was also no relation between participants' height estimates and their SUDS ratings, $p=.55$.

Linear mixed models (LMM) were used to calculate the intercepts and slopes for the ratios of perceived to actual size over the different targets sizes. This statistical method was chosen because it computes model parameter estimates (intercept and slope) while taking into account the repeated measures nature of the data. Separate LMM were computed for the low- and high-fear SUDS conditions. Intercept and participant were specified as random factors and target size was specified as a fixed factor. In addition, LMM allows for the specification of the appropriate variance structure (see Moser, 2004; Singer, 1998). An unstructured variance matrix provided the best fit for both models, indicating the residuals were not highly correlated in either SUDS condition.

The slope of the low-fear SUDS condition, $B_{1}=-.022, S E=$ $.002, t(32)=9.73, p<.001$, was significantly different from zero, as was the slope of the high-fear condition, $B_{1}=-.002, S E=$ $.003, t(38)=5.60, p<.001$. Most importantly, the slope of the low-fear condition was reliably steeper than that for the high-fear condition, $t(70)=17.81, p<.001, d=0.30, R^{2}=.08$ (see Figure 8). Both the intercept for the low-fear condition, $B_{O}=1.623, S E=$ $.048, t(32)=33.93, p<.001$, and high-fear condition, $B_{O}=$ $1.623, S E=.087, t(38)=18.61, p<.001$, were greater than zero. However, no reliable difference was found between intercepts, $t(70)=.04, p=.97, d=.02, R^{2}<.01$. The slope results indicate fear differentially affects the function of size perception, with the gap in perceived size between the high- and low-fear groups increasing as targets become larger.

Although the data in both conditions do not appear particularly linear, nonlinear models were overspecified. This overspecification is probably due to having only four size estimates per participant. With an increased number and range of size estimates, it is certainly plausible that power functions with negative exponents could provide the best fit for both fear groups. However, all size functions are likely to asymptote at 1 , given that under full-cue viewing conditions size is going be bounded by a ratio of 1 . Given the miniscule effect size for the intercepts between groups $\left(R^{2}<\right.$ .01 ), no statistical evidence was found to support the notion that effects of fear on size perception can be attributed to a simple linear shift.

\section{Discussion}

This experiment replicated the size results of Experiments 1A and $1 \mathrm{C}$ with a variety of target sizes, in that participants who stood on the balcony overestimated size more than did those who stood on the ground. However, the overestimation of size in this experiment was greater overall than in the previous experiments. We believe this may be due to the changed procedure, in which participants had to turn more to complete the matching task, or it could also be related to the increased time spent on the height. A horizontal- (control) viewing condition was added, and the distance and size estimates for the horizontal-viewing condition were within the expected range. Therefore, it is unlikely that there was something special about the targets that produced a size overestimation in previous experiments. Participants also overestimated height more from the top than the bottom, also replicating Experiments $1 \mathrm{~A}$ and $1 \mathrm{C}$. However, a horizontal distance of the same extent as the balcony was underestimated, which is what was expected, based on previous research (Amorim, Loomis, \& Fukusima, 1998; Cutting \& Vishton, 1995; Loomis, Da Silva, Fujita, \& Fukusima, 1992; Norman, Todd, Perotti, \& Tittle, 1996).

Participants' estimates of size were related to their state-level ratings of fear. Participants who overestimated size were more likely to report feeling afraid of the height. This correlation was driven by participants who viewed the height from the top. Importantly, LMM analyses revealed that fear influenced the slope of the function of size estimates, not the intercept of the functions. This finding suggests that fear differentially influences the func-

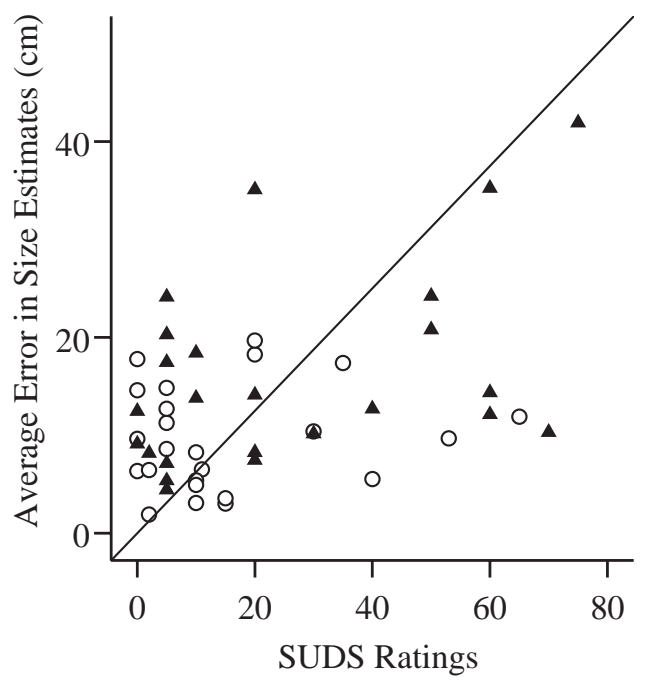

Figure 7. Relationship between the average error in size estimates and state-level ratings of fear on the Subjective Units of Distress Scale (SUDS) for the top (triangles) and bottom (circles) viewing conditions of Experiment 2 . 


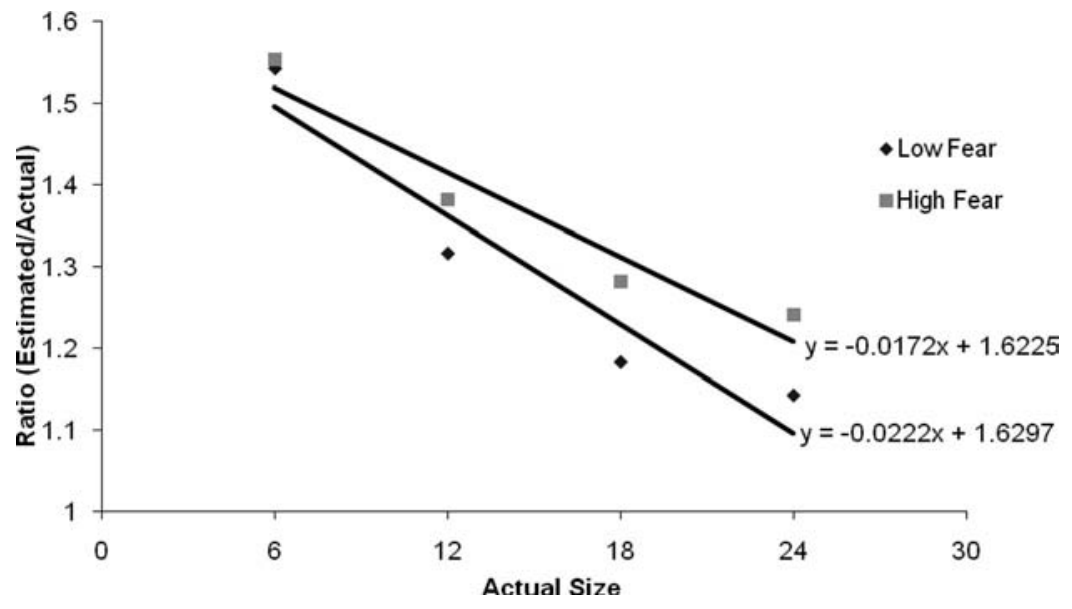

Figure 8. Mean values for each condition are shown by actual size and the ratio of perceived to actual size. Slope and intercept parameters were computed from the entire set of data using LMM.

tion of size estimates and is not due to a general tendency, in people who are afraid, to report every size as larger.

There was no correlation between the trait-level ratings of fear and the overestimation of height for participants who viewed from the top or the bottom. A possible explanation for this null result is that participants gave their height estimate after estimating the size of each of the targets. The exposure time to the height was much longer in this experiment than in previous experiments because participants had to make many size estimates before making the height estimate and the fear estimate. This additional exposure time may have resulted in habituation to the height; accordingly, participants' ratings of fear may have been reduced or conservative.

\section{Experiment 3: Triangulated-Walking Measure of Height From Top- and Bottom-Viewing Angles}

This experiment tested whether people overestimated heights with a visually directed action measure. Heights viewed from the top should be overestimated with a triangulated-walking measure, given that this task is an indirect measure of distance perception (Fukusima, Loomis, \& Da Silva, 1997; Loomis et al., 1992). However, as stated previously, this task may measure apparent location rather than apparent distance. This is particularly true when an observer is standing at the top of a vertical extent because eye height information cannot be substituted for distance information as it can be when an observer is on the ground plane. Overall, this measure was employed because it is indirect and is not likely to be influenced by cognitions. Thus, participants would not have easily inferred the expected results and would not have been able to bias their responses accordingly. Moreover, blindwalking is a visually guided action measure of distance perception that is usually accurate (Fukusima et al.; Loomis et al.). Therefore, we wanted to test whether a relatively unbiased measure of distance perception, which also involved action, could be influenced by viewing a vertical extent rather than a horizontal one.

Given the results of preliminary experiments done by Dilda, Creem-Regehr, and Thompson (2006), a large overestimation of height was not predicted when viewing and blindwalking from the bottom. Dilda et al. showed that blindwalked estimates of the distance to targets placed on a ceiling were accurate up to approximately $6 \mathrm{~m}$. However, in this experiment, the degree of fear associated with the height was hypothesized to correlate with the amount of overestimation in the walking measure.

\section{Method}

Participants. Twenty-eight University of Virginia undergraduates (19 women, 8 men) participated in the experiment for $\$ 5$ or to satisfy a course requirement. There were 11 women in the bottom-viewing condition and 8 in the top-viewing condition. There were 3 men in the bottom-viewing condition and 5 in the top-viewing condition. Due to experimenter error, data for the SUDS and AQ were not recorded for two participants.

Apparatus. Participants viewed the orange target disk used in the previous experiments from the same balcony as described in Experiment 1A. A blindfold was given to participants to perform the blindwalking task. A tape measure was used to measure the distance walked by the participant.

Procedure. Participants were randomly assigned to either the top- or bottom-viewing condition. The target was displaced $9 \mathrm{~m}$ to the left of the participants' viewing positions when they were on the top and to the right of the participants' viewing positions when they were on the bottom. The participant viewed the target from this alternate position and then walked without vision along a straight, oblique path until the participant believed he or she was directly above or below the target's location (methodology adapted from Loomis et al., 1992, see Figure 9). The distance that the observer walked served as his estimate of perceived distance to the target. In both conditions, the experimenter walked next to the participant while they blindwalked so as to limit veering from a straight path and to ensure safety. After participants completed the estimate, their walked distance was measured with the tape measure. All participants gave a SUDS rating after blindwalking to the target and completed the AQ after giving their blindwalked and SUDS estimates. 


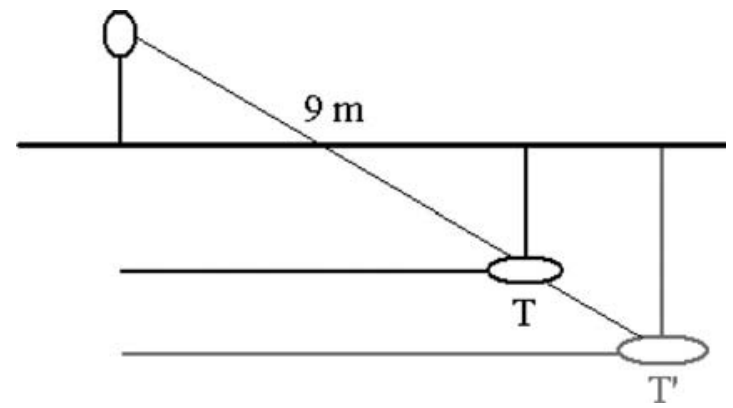

Figure 9. Diagram of the placement of the target disk (T) relative to the observer in Experiment 4. $\mathrm{T}^{\prime}$ represents the perceived location of the target when the distance to the target is overestimated. Therefore, when participants are asked to walk to a location directly above the target, they should walk further if they are overestimating distance (stopping over T' instead of over T).

\section{Results}

Height. Participants in the top-viewing condition walked significantly farther than participants in the bottom-viewing condition (see Figure 10). A one-way ANOVA showed that blindwalked estimates of distance on the top $(M=11.84, S D=2.11)$ were significantly larger than those on the bottom $(M=8.88, S D=$ $1.04), F(1,26)=22.26, p<.0001, \eta_{p}^{2}=0.44$. Participants who viewed the height from the top overestimated the distance to walk by $30 \%$, whereas participants who viewed the height from the bottom underestimated the distance to walk by $2 \%$.

Fear. As in most of the previous experiments, participants' scores on the AQ and their SUDS ratings were highly correlated, $r(26)=0.79, p<.0001$. There was no relation between SUDS ratings and blindwalked estimates on the top, $p=.90$, or the bottom, $p=.70$. There was also no relation between participants' blindwalked estimates of height and their scores on the AQ for the top, $p=.85$, or the bottom, $p=.65$.

\section{Discussion}

With an indirect, visually guided action measure of distance, heights were overestimated more from the top than from the bottom. In this experiment, participants who viewed from the bottom were fairly accurate when blindwalking to the location of the target. This result was not surprising given recent research by Dilda et al. (2006). However, the overestimation of distance from the top is surprising, because participants in the top condition were likely scared when they walked blindfolded on the balcony. The anxiety associated with walking blindfolded on a balcony could have resulted in an underestimation, so the distance walked by participants may have been conservative even though it was overestimated. Interestingly, the height overestimation in this experiment was less than in the previous experiments by a small amount. The fear associated with walking on the height may have attributed to the reduction of the effect.

State- and trait-level fear ratings did not correlate with the blindwalked estimates of height. This result was expected for estimates made from the bottom, but not for those made from the top. However, participants in this experiment had a much shorter exposure period to the height, so this lack of exposure could be a factor in the lack of correlation. Additionally, participants did not look straight over the railing in this experiment as in previous experiments. Instead, they had to look down and to their side, so leaning over the railing was less prevalent. Because the leaning is likely to increase feelings of fear, the participants in this experiment may not have experienced the same level of fear as in previous experiments. Or, it is possible that visually guided action measures are not influenced by fear in the same manner as visually matched distance or size estimates.

\section{General Discussion}

The experiments reported in this article support the hypothesis that heights are consistently and reliably overestimated more from the top than the bottom. Experiment $1 \mathrm{~A}$ and $1 \mathrm{C}$ demonstrated that heights are overestimated more from the top using both direct and indirect measures of vertical extent in two different locations. Experiment 1B showed that this overestimation from the top was smaller when the height was small. Experiment 1B also demonstrated that, in general, the act of looking down did not produce the overestimation seen in Experiments $1 \mathrm{~A}$ and 1C. Experiment 2 replicated Experiments $1 \mathrm{~A}$ and $1 \mathrm{C}$ using multiple target sizes. All of the sizes were overestimated from the top, but not from the bottom. A horizontal-viewing condition was also added as a control, and the results replicated previous findings in the perception of spatial layout: Horizontal distances were slightly underestimated and size estimates from a horizontal distance were fairly accurate. Therefore, the specific targets used in these experiments did not produce the overestimation of size. Experiment 3 replicated the overestimation of height from the top with another indirect measure of extent: triangulation by blindwalking. In this experiment, participants estimated height by walking until they believed they were directly above or below a target that was displaced from them horizontally. Participants who viewed the target from the top of the balcony overshot it, suggesting an overestimation of the perceived vertical distance to the target.

With regard to fear influencing height, correlational data in Experiment $1 \mathrm{~A}$ revealed that the overestimation of height was related to both state- and trait-level fear. People who were afraid overestimated height more than people who were unafraid. These

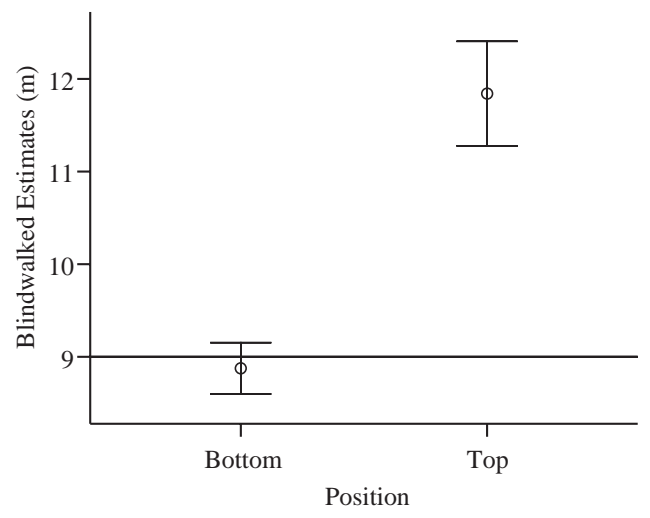

Figure 10. Blindwalked estimates of distance for the top and bottom viewing conditions in Experiment 4. The line denotes the actual distance to the target $(9 \mathrm{~m})$. The bars represent one standard error of the mean. 
results were partially replicated in Experiments $1 \mathrm{C}$ and 2. In those experiments, participants who reported higher state-level fear overestimated the size of the targets more. In Experiment 3, participants' height and size estimates did not correlate with their state- or trait-level reports of fear. Further discussion of the findings and lack of findings for an influence of fear on perception will be discussed after discussion of the primary finding: Heights are overestimated more from the top than the bottom.

\section{Optical Cues to Distance and the Overestimation of Height}

The major finding of this article is that the overestimation of heights from the top compared to the bottom is extremely large when considered in the context of other normative biases in the perception of spatial layout. For instance, the maximum overestimation of height observed in the horizontal-vertical illusion in the real world is only 10 to15\% (Yang et al., 1999). Similarly, maximum distance underestimation in outdoor environments is typically 10\% (Amorim et al., 1998; Cutting \& Vishton, 1995; Loomis et al., 1992; Norman et al., 1996). In the experiments presented, the overestimation of height from the top was greater than $30 \%$ for each of the locations and measures employed. Why was the overestimation so large? There are a variety of reasons why people may overestimate heights more from the top than the bottom. First, the top view lacks optical variables that often specify depth on the horizontal ground plane. For example, texture gradient is difficult to see when looking down from the top of the balcony, but easy to see from the bottom of the balcony looking up (see Figure 11). Therefore, the texture gradient provided by the bricks of the building could be a valuable cue to distance when viewing from the bottom. Likewise, the horizon and the observer's eye height are useless cues for distance when viewing from the top because the observer is not standing on a true ground plane. As stated at the beginning of this article, the reduction of optical cues to distance usually leads to an underestimation of distance with a variety of distance measures (Gogel, 1965; Philbeck \& Loomis, 1997). Assuming the overestimation of height in these experiments was due to the lack of optical cues for distance from the top, then it would be interesting to directly manipulate optical variables to test that assumption in future studies. ${ }^{1}$
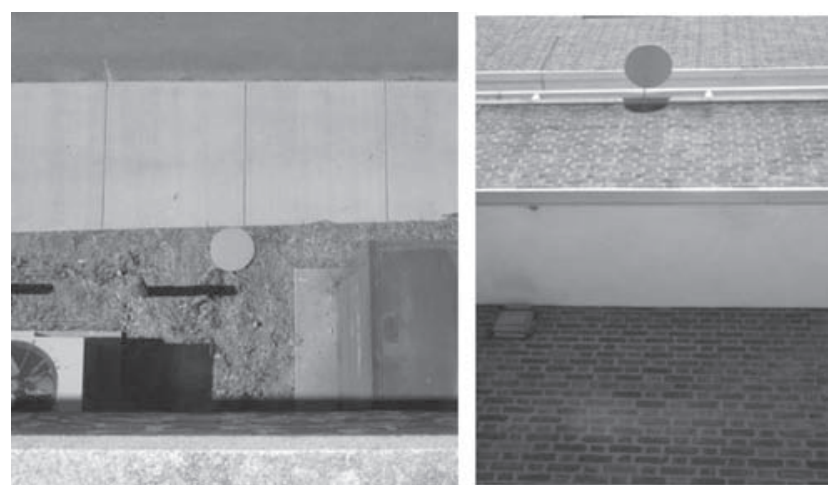

Figure 11. View of the target disk from the top and bottom. Texture gradient is more apparent from the bottom than the top (e.g., the bricks).
That people overestimated heights from the top-from an impoverished viewing condition with respect to available cues to scale distances-was surprising and challenges predictions from previous research on horizontal distance estimation in reduced-cue environments. Even if viewing the height from the top was considered a full-cue viewing condition, the results would be surprising, because most studies show accurate distance perception in full-cue environments with a variety of measures (Elliott, 1987; Fukusima et al., 1997; Gogel \& Tietz, 1979; Loomis et al., 1992; Rieser et al., 1990; Thomson, 1980, 1983).

\section{Does Fear Influence the Overestimation of Height?}

Another possible reason why the reduction of cues to distance resulted in an over- rather than an underestimation is that participants' fear may have affected their height perceptions. If physiological fear is influential in the scaling of perceived height, then participants would be more likely to overestimate than underestimate. Previous work showed that participants were more likely to overestimate an uphill distance than the same distance on flat ground, even when geometry predicted that they should underestimate up-hill extents (Stefanucci et al., 2005). This overestimation was attributed to the role of bio-energetic effort in scaling perceived distances. Participants may have overestimated uphill distances due to the increased effort associated with ascending hills as opposed to walking on level ground. In a similar vein, fear may play a role in perceiving large, potentially dangerous, vertical extents.

The evidence in these studies regarding the influence of fear on perception is inconclusive. The results of Experiments 1A, 1C, and 2 are surprising in that they were obtained with students who were, on average, not afraid of heights. However, as Jackson and Cormack (2007) discussed, perceiving heights to be taller from the top has obvious evolutionary advantages. We believe that a better way to approach the question of whether fear influences the perception of height would be to test groups of individuals who are more or less afraid of heights. In fact, research done with collaborators in clinical psychology found that people with a higher trait-level fear of heights show increased overestimation of heights from the top in normative situations and when the consequences of the heights are magnified with an imagery task (Clerkin, Cody, Stefanucci, Proffitt, \& Teachman, 2008; Teachman, Stefanucci, Clerkin, Cody, \& Proffitt, 2008).

Recent research also suggests that fear may not only influence perception but also behavior in height environments. A set of studies conducted by Pijpers, Oudejans, Holsheimer, and Bakker (2003) found that anxiety associated with rock climbing produced both physiological and behavioral changes in novice climbers. Climbers who were asked to take a higher route on the climbing wall (as opposed to a lower, safer route) exhibited significantly

\footnotetext{
${ }^{1}$ We are not arguing that all cues for distance perception are lost when standing at the top of a height. Motion parallax can be used to discover the depth of the object on the ground, familiar size could be used when the object at the base of the height is familiar, and occlusion, whether it is dynamic or static, can provide information about depth to an object on the ground. Moreover, the availability of other cues to distance, like texture gradient, will vary depending on the location of the height and the information available.
} 
higher heart rates, more muscle fatigue, and higher blood lactate concentrations. The climbers who took the higher route also took longer to climb the route (even when route distance was equated), suggesting that the anxiety influenced their behavioral performance. In more recent work, this group has found that maximum reachability of climbers was influenced by anxiety, which also resulted in the use of more holds while actually climbing (Pijpers, Oudejans, Bakker, \& Beek, 2006). They also showed that climbers who were more anxious detected fewer lights in an attention task performed during climbing. Overall, their results suggest that anxiety can influence the perception of affordances. We believe that novice climbers would also perceive the heights as higher than advanced climbers and that this would be an interesting future study to pursue.

Finally, recent work on the influence of fear on distance perception manipulated one component of fear-arousal-to ascertain whether it was sufficient to produce changes in both height and horizontal distance perception (Stefanucci \& Storbeck, 2008). Interestingly, the findings showed that participants who were aroused from viewing arousing images overestimated a height from the top, but not a horizontal extent, when compared to participants who were not aroused. This suggests that the perception of horizontal extents may be unaffected by manipulations of arousal. An important step would be to identify whether certain fear manipulations that are relevant for horizontal distance estimation might affect the perception of distance on flat ground. For example, if people were asked to judge distances either to a fearful object or across a fearful object (like a spider or snake), than they may show differences in horizontal distance perception (i.e., people with spider fear may be more likely to judge the distance to a spider as shorter than people who are unafraid).

\section{Conclusions}

Two important findings emerge from this article. First, heights are overestimated more from the top than the bottom. This overestimation is robust and proportionally larger than most other normative biases in the perception of spatial layout. Moreover, because the overestimation occurs using both direct and indirect measures of perception, there is good reason to believe that a perceptual bias rather than a cognitive bias causes this overestimation.

Secondly, the results preliminarily indicate that fear may influence the overestimation of height. In three of the experiments the overestimation correlated with reports of fear. Though the fear results were mixed, the preliminary evidence for an influence of fear on the perception of height is promising and is being followed up (Stefanucci \& Storbeck, 2008; Teachman et al., 2008). Further investigation is needed before an influence of fear on height perception can be realized.

\section{References}

Amorim, M.-A., Loomis, J. M., \& Fukusima, S. S. (1998). Reproduction of object shape is more accurate without the continued availability of visual information. Perception, 27, 69-86.

Andre, J., \& Rogers, S. (in press). Using verbal and blind-walking distance estimates to investigate the two-visual systems hypothesis. Perception \& Psychophysics.

Bunnell, L. H. (1990). Discovery of the Yosemite. Yosemite National Park,
CA: Yosemite Association. (Reprinted from Discovery of the Yosemite, and the Indian war of 1851, which led to that event, 3d ed. 1892, New York: F. H. Revell).

Clerkin, E. M., Cody, M. W., Stefanucci, J. K., Proffitt, D. R., \& Teachman, B. A. (2008). Imagery and fear influence height perception. Manuscript submitted for publication.

Cohen, D. C. (1977). Comparison of self-report and behavioral procedures for assessing acrophobia. Behavior Therapy, 8, 17-23.

Corlett, J. T., Patla, A. E., \& Williams, J. G. (1985). Locomotor estimation of distance after visual scanning by children and adults. Perception, 14, 257-263.

Cutting, J. E., \& Vishton, P. M. (1995). Perceiving layout and knowing distances: The integration, relative potency, and contextual use of different information about depth. In W. Epstein \& S. J. Rogers (Eds.), Perception of space and motion. Handbook of perception and cognition (2nd ed., pp. 69-117). San Diego, CA: Academic Press.

Dilda, V., Creem-Regehr, S. H., \& Thompson, W. B. (2006). Angle of elevation influences distance perception to targets on the ceiling [Abstract]. Journal of Vision, 6(6), 420a.

Elliott, D. (1987). The influence of walking speed and prior practice on locomotor distance estimation. Journal of Motor Behavior, 19, 476485.

Epstein, W. (1973). The process of "taking into account" in visual perception. Perception, 2, 267-285.

Epstein, W. (1977). Stability and constancy in visual perception: Mechanisms and processes. New York: Wiley.

Epstein, W., Park, J., \& Casey, A. (1961). The current status of the size-distance hypotheses. Psychological Bulletin, 58, 491-514.

Fukusima, S. S., Loomis, J. M., \& Da Silva, J. A. (1997). Visual perception of egocentric distance as assessed by triangulation. Journal of Experimental Psychology: Human Perception and Performance, 23, 86-100.

Gilinsky, A. (1951). Perceived size and distance in visual space. Psychological Review, 58, 460-482.

Gilinsky, A. (1955). The effect of attitude upon the perception of size. American Journal of Psychology, 68, 173-192.

Gogel, W. (1965). Equidistance tendency and its consequences. Psychological Bulletin, 64, 153-163.

Gogel, W. C., \& Tietz, J. D. (1979). A comparison of oculomotor and motion parallax cues of egocentric distance. Vision Research, 19, 11611170.

Hekmat, H. (1987). Origins and development of human fear reactions. Journal of Anxiety Disorders, 1, 197-218.

Hennepin, N. (1903). New discovery of a vast country in America, extending above four thousand miles, between New France and New Mexico, Reuben Gold Thwaites, Ed. Reprinted from the 2nd London issue, 1698. Vols. 1-2. Chicago: A. C. McClurg \& Co.

Holway, A. H., \& Boring, E. G. (1941). Determinants of apparent visual size with distance variant. American Journal of Psychology, 54, 21-37.

Jackson, R. E., \& Cormack, L. K. (2007). Evolved navigation theory and the descent illusion. Perception \& Psychophysics, 69, 353-362.

Kilpatrick, F. P.; Ittelson, W. H. (1953) The size-distance invariance hypothesis. Psychological Review, 60, 223-231.

Leibowitz, H. W., \& Harvey, L. O. (1967). Size matching as a function of instructions in a naturalistic environment. Journal of Experimental Psychology, 74(3), 378-382.

Leibowitz, H. W., \& Harvey, L. O. (1969). Effect of instructions, environment, and type of test object on matched size. Journal of Experimental Psychology, 81(1), 36-43.

Loomis, J. M., Da Silva, J. A., Fujita, N., \& Fukusima, S. S. (1992). Visual space perception and visually directed action. Journal of Experimental Psychology: Human Perception \& Performance, 18, 906-921.

Menzies, R. G., \& Clark, J. C. (1995). Danger expectancies and insight in acrophobia. Behaviour Research and Therapy, 33, 215-221.

Moser, E. B. (2004, May). Repeated measures modeling with PROC 
MIXED. In Proceedings of the 29th SAS Users Group International Conference, Montreal, Canada. Available online at http:// www2.sas.com/proceedings/sugi29/188-29.pdf

Norman, J. F., Todd, J. T., Perotti, V. J., \& Tittle, J. S. (1996). The visual perception of three-dimensional length. Journal of Experimental Psychology: Human Perception \& Performance, 22, 173-186.

Philbeck, J. W., \& Loomis, J. M. (1997). Comparison of two indicators of perceived egocentric distance under full-cue and reduced-cue conditions. Perception \& Psychophysics, 59(4), 601-612.

Pijpers, J. R., Oudejans, R. R. D., Bakker, F. C., \& Beek, P. J. (2006). The role of anxiety in perceiving and realizing affordances. Ecological Psychology, 18, 131-161.

Pijpers, J. R., Oudejans, R. R. D., Holsheimer, F., \& Bakker, F. C. (2003). Anxiety-performance relationships in climbing: A process-oriented approach. Psychology of Sports and Exercise, 4, 283-304.

Proffitt, D. R., Bhalla, M., Gossweiler, R., \& Midgett, J. (1995). Perceiving geographical slant. Psychonomic Bulletin \& Review, 2, 409-428.

Proffitt, D. R., Stefanucci, J., Banton, T., \& Epstein, W. (2003). The role of effort in perceiving distance. Psychological Science, 14(2), 106-112.

Proffitt, D. R., Stefanucci, J., Banton, T., \& Epstein, W. (2007). Reply to Hutchison and Loomis. The Spanish Journal of Psychology, 9, 340-342.

Rachman, S., \& Cuk, M. (1992). Fearful distortions. Behavioral Research Therapy, 30, 583-589.

Radomsky, A. S., Teachman, B., Baker, V., \&. Rachman, S. (1996, November). Perceptual and cognitive distortions of feared stimuli. Poster session presented at the annual meeting of the Association for the Advancement of Behavior Therapy, New York, NY.

Rieser, J. J., Ashmead, D. H., Talor, C. R., \& Youngquist, G. A. (1990). Visual perception and the guidance of locomotion without vision to previously seen targets. Perception, 19, 675-689.

Riskind, J. H., Kelly, K., Moore, R., Harman, W., \& Gaines, H. (1992). The looming of danger: Does it discriminate focal phobia and general anxiety from depression? Cognitive Therapy and Research, 16, 1-20.

Rock, I. (1975). Indirect perception. Cambridge, MA: MIT Press.

Sedgwick, H. A. (1986). Space perception. In K. R. Boff, L. Kaufman, \& P. J. Thomas (Eds.) Handbook of perception and performance (Vol. 1: Sensory processes and perception). Pp. 21.1-21.57. New York: Wiley.

Sinai, M. J., Ooi, T. L., \& He, Z. J. (1998). Terrain influences the accurate judgment of distance. Nature, 395, 497-500.

Singer, J. D. (1998). Using SAS PROC MIXED to fit multilevel models, hierarchical models, and individual growth models. Journal of Education and Behavioral Statistics, 24(4), 323-355.

Steenhuis, R. E., \& Goodale, M. A. (1988). The effects of time and distance on accuracy of target-directed locomotion: Does an accurate short-term memory for spatial location exist? Journal of Motor Behavior, 20, 399-415.

Stefanucci, J. K., Proffitt, D. R., Banton, T., \& Epstein, W. (2005) Distances appear different on hills. Perception \& Psychophysics, 67(6), 1052-1060.

Stefanucci, J. K., Proffitt, D. R., Clore, G., \& Parekh (2008). Skating down a steeper slope: Fear influences the perception of geographical slant. Perception, 37, 321-323.

Stefanucci, J. K., \& Storbeck, J. (2008). Don't look down: Emotional arousal elevates height perception. Manuscript submitted for publication.

Teachman, B. A., Stefanucci, J. K., Clerkin, E. M., Cody, M. W., \& Proffitt, D. R. (2008). A new mode of fear expression: Perceptual bias in height fear. Emotion, 8, 296-301.

Thomson, J. A. (1980). How do we use visual information to control locomotion? Trends in Neurosciences, 3, 247-250.

Thomson, J. A. (1983). Is continuous visual monitoring necessary in visually guided locomotion? Journal of Experimental Psychology: Human Perception \& Performance, 9, 427-443.

van Ulzen, N. R., Semin, G. R., Oudejans, R. R. D., \& Beek, P. J. (2008) Affective stimulus properties influence size perception and the Ebbinghaus illusion. Psychological Research, 72, 304-310.

Wraga, M. \& Proffitt, D.R. (2000). Mapping the zone of eye height utility for seated and standing observers. Perception, 29, 1361-1383.

Weerts, T. C., \& Lang, P. J. (1978). Psychophysiology of fear imagery: Differences between focal phobia and social performance anxiety. Journal of Consulting \& Clinical Psychology, 46, 1157-1159.

Witt, J. K., Proffitt, D. R., \& Epstein, W. (2004). Perceiving distance: A role of effort and intent. Perception, 33(5), 577-590.

Yang, T. L., Dixon, M. W., \& Proffitt, D. R. (1999). Seeing big things: Overestimation of heights is greater for real objects than for objects in pictures. Perception, 28, 445-467.

Received September 6, 2007

Revision received July 22, 2008 Accepted July 29, 2008 